\title{
Análise das externalidades na produção de serviços pela perspectiva do modelo de produção mais limpa
}

Este artigo tem por objetivo descrever como a aplicação da perspectiva de Produção Mais Limpa (PML) interfere na visão das externalidades advindas de um processo de produção de serviços. Para tanto, buscou-se como procedimentos metodológicos a pesquisa de caráter exploratório com abordagem qualitativa, ou seja, com base em pesquisa bibliográfica e documental construiu-se as categorias de análise e posterior construção de um esquema para a avaliação do fluxo da produção de serviços. Nesse caso utilizou-se para o estudo a prestação de serviços de recebimento de faturas por uma instituição bancária. Ao tratar desse processo sob a perspectiva de PML verificou-se a existência de externalidades antecedentes e consequentes positivas ao se adotar o sistema eletrônico de pagamentos de faturas. A contribuição desta perspectiva é que ao utilizar o método de PML pode planejar a produção de serviços de forma mais sustentável, pois a visão da criação e produção de forma sistêmica e circular pode evidenciar o papel de cada agente nos três níveis propostos neste processo.

Palavras-chave: Externalidades; Cleaner Production; Produção Mais Limpa; Serviço; Produção.

\section{Analysis of externalities at production services by perspective the cleaner production model}

\begin{abstract}
This article aims to describe the application of Cleaner Production methodology (PML) interferes with externalities resulting from a process of production services. Therefore, we sought as methodological procedures to exploratory research with qualitative approach, i.e., based on bibliographical and documentary research built the categories of analysis and subsequent construction of a scheme for evaluating the flow of production services. In this case it was used to study the provision of receiving invoices services by a bank. By treating this process from the perspective of PML verified the existence of antecedents and consequences positive externalities by adopting the electronic system invoice payments. This PML perspective can assist in planning and production more sustainable services for the vision of creating and producing systemic way and circular can highlight the role of each agent in the three levels proposed in this new process.
\end{abstract}

Keywords: Cleaner Production; Service; Production

\section{Topic: Consumo e Meio Ambiente}

Reviewed anonymously in the process of blind peer

Luciano Ferreira da Silva

Pontifícia Universidade Católica de São Paulo

http://lattes.cnpq.br/3790925273077368

If_silvabr@yahoo.com.br

Arnoldo José de Hoyos Guevara

University of California System, UC System, Estados Unidos

http://lattes.cnpq.br/1249843121429282

arnoldodehoyos@yahoo.com.br

Pedro Fernandes Saad

Pontifícia Universidade Católica de São Paulo

http://lattes.cnpq.br/0214654850405679

pedro@editorabrasileira.com.br

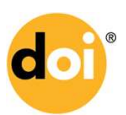

DOI: 10.6008/SPC2179-6858.2016.001.0002
Received: $\mathbf{1 8 / 1 1 / 2 0 1 5}$

Approved: 20/11/2015

Paulo Sergio Gonçalves de Oliveira

Universidade Metodista de Piracicaba http://lattes.cnpq.br/5787786955978812

psgoliveira@hotmail.com

Referencing this:

SILVA, L. F.; GUEVARA, A. J. H.; SAAD, P. F.; OLIVEIRA, P. S. G.. Análise das externalidades na produção de serviços pela perspectiva do modelo de produção mais limpa. Revista Ibero-Americana de Ciências Ambientais, v.7, n.1, p.29-41, 2016. DOI:

http://doi.org/10.6008/SPC2179-6858.2016.001.0002 


\section{INTRODUÇÃO}

A ação de produzir e consumir gerando prejuízos ao planeta não é mais uma opção facilmente aceitável, pois as consequências à saúde, ao bem estar e a própria sobrevivência geram uma pressão cada vez maior tanto em sociedades em desenvolvimento, quanto em países chamados de desenvolvidos. Logo, para instituir uma sociedade mais sustentável é necessário modificar os paradigmas convencionais de produção e consumo.

Segundo dados do Instituto Akatu o consumo humano já supera em $25 \%$ a capacidade de renovação dos recursos naturais no planeta, sendo que para manter estes padrões serão necessários em menos de 50 anos dois planetas Terra para atender as demandas por água, energia e alimento (AKATU, 2008). Assim, o processo de produzir somente para atender um desejo hedonista dos indivíduos pode causar danos irreversíveis à sociedade. Sendo que este sistema que de um lado extrai e consome os recursos não renováveis do planeta acima de sua capacidade de resiliência. De outro lado estimula cada vez mais a criação e produção de bens e serviços com elevadas taxas de imissão de gases de efeito estufa.

Portanto, se faz necessário compreender que apesar da criação e a produção de bens e serviços sejam o resultado de um processo interno da empresa, estas atividades devem ser revistas relacionando-as a toda cadeia de produção. De tal modo, este sistema que contraria os modelos convencionais sofre a influência de outros atores como o Estado, a concorrência, consumidor, entre outros que desempenham algum papel na produção, consumo, reciclagem e reaproveitamento dos produtos (BAUMANN, BOONS, BRAGD, 2002; FÖRSTER, 2015).

Deste modo, a preocupação com a sustentabilidade do planeta na produção e consumo se torna cada vez mais um item importante na pauta de governos, empresas e ONGs. Um exemplo da relevância desta questão está no pronunciamento sobre o plano de energia limpa do presidente dos EUA, Barack Obama, em agosto de 2015. O presidente Obama intenciona com este plano proteger a saúde pública reduzindo a emissão de dióxido de carbono nos EUA em 32\% até 2030 (WHITE HOUSE, 2015).

A discussão sobre a produção de forma sustentável está em pauta em acordos comerciais, em planos de negócios e nos currículos das universidades. Contudo, esta questão surge principalmente quando se trata da produção de bens manufaturados. Sendo justamente este o motivo que torna relevante discutir a produção sustentável de serviços.

De acordo com o Sistema de Contas Nacionais do Brasil, em 2012 e 2013 a participação dos serviços no PIB (Produto Interno Bruto) foi de 68,5\% e 69,3\% respectivamente (G1, 2014). Além disso, o que induziu a tratar a produção de serviços pela perspectiva do modelo de PML (Produção Mais Limpa) foi a alta concentração de trabalhos no setor industrial. A pesquisa de Vanrandas Junior, Miguel e Carvalho (2011) confirma a maior concentração de pesquisas no processo de produção de bens, bem como também o trabalho de D'Aguino et al. (2014) que ressalta as pesquisas na manufatura industrial.

Portanto, ao discutir o modelo de PML para a produção de serviços, abre-se oportunidades para lidar com o setor que neste século XXI mais emprega e contribui para o PIB dos países. Não obstante, as 
particularidades do setor de serviços requerem perspectivas mais abrangentes com relação ao seu processo, uma vez que as especificidades de sua produção envolvem uma ação ou desempenho por parte do prestador. O que difere da produção de bens onde ocorre a entrega de um objeto tangível aos seus consumidores.

Desse modo, ao ampliar a perspectiva para o desenvolvimento de serviços utilizando PML serão incentivadas a manutenção e a melhoria na utilização dos recursos naturais pelas empresas, além da reorientação no desenvolvimento de tecnologias para uma produção mais sustentável. O que também requer um esforço social abrangente para conservar os estoques remanescentes destes recursos do planeta, além de tornar o seu uso mais inteligente e sustentável.

Contudo, para que ocorra um maior incremento de práticas de produção e consumo mais sustentáveis de forma global, se faz necessário entender de forma sistêmica o ambiente em que as organizações estão inseridas ou mesmo o local de onde retiram os seus recursos (SUKHDEV, 2013; GHOSAL, 2015). Aliás, vale destacar que estas consequências oriundas da produção e consumo, que podem ser negativos ou positivos para a sociedade, são denominadas de externalidades (SUKHDEV, 2013). As externalidades são representadas pelo custo ou benefício que um agente impõe a terceiros, quando da realização de uma atividade econômica (COELHO, 2012; GONÇALVES; RIBEIRO 2013).

Com base nessa discussão sobre a utilização dos recursos do planeta, e na questão das externalidades negativas geradas do processo de produção e consumo de serviços, pode ser entendido a importância da implementação de processos que contemplem a metodologia de PML (CNTL, 2003; UNITED, 2007; PIMENTA; GOUVINHAS, 2012; OLIVEIRA NETO; LEITE; BAPTISTA, 2014).

Deste modo, este estudo de caráter exploratório com abordagem qualitativa visará responder a seguinte pergunta problema: Como a PML pode influenciar nas externalidades negativas geradas na produção de serviços? Para tanto, buscar-se-á alcançar como objetivo geral descrever a relação entre a inserção de práticas de PML e as externalidades geradas no processo de produção de serviços de pagamentos bancários.

Portanto, ao rever as práticas de produção e consumo sob a perspectiva dos conceitos de PML é possível discutir a aplicação de operações sustentáveis pelos agentes produtores de bens e serviços, bem como sua interação em toda cadeia, da extração dos insumos ao consumo final (CNTL, 2003; PAREJA, 2010; FABI; LOURENÇO, SILVA, 2010; PIMENTA; GOUVINHAS, 2012; OLIVEIRA NETO; LEITE; BAPTISTA, 2014,).

\section{REVISÃO TEÓRICA}

\section{As Externalidades da Produção e Aplicação de PML (Produção Mais Limpa)}

O cenário relacionado às decisões econômicas surge da relação entre as necessidades humanas ilimitadas e a restrição física dos recursos. No entanto, tomando como pensamento norteador a escassez, pode-se inferir que esta sociedade não terá recursos suficientes para suprir todas as suas necessidades no futuro (CAVALCANTI, 2004; HU et al., 2011). Para os estudos sobre os fluxos entre os agentes econômicos, a 
perspectiva macroeconômica determina que as limitações apontadas na quantificação dos bens ambientais reproduzem-se e ampliam-se fortemente por que o contexto envolve grandes agregados macroeconômicos. A posse e transformação de recursos naturais, como o uso de matérias-primas no processo de produção global, favorecem o desperdício e a privação de recursos para a atividade humana (HARTMAN; STAFFORD, 1997; SEN, 2000; JAPPUR, 2004).

Todavia, vale destacar que a economia do meio ambiente sustenta-se na economia neoclássica segundo a qual os danos ecológicos advêm das imperfeições dos mercados (SEN, 2000; CAVALCANTI, 2010; COELHO, 2012). Assim, para proteger os recursos naturais, a economia ambiental propõe a valoração dos recursos, a correção dos preços e a contabilização da deterioração ambiental. Porém, isto não é uma tarefa fácil por que esta ação deve levar em conta a incomensurabilidade de muitos bens ambientais. Isso acontece por causa da natureza de alguns elementos que não podem ser quantificados ou valorados no processo produtivo (SEN, 2000; ANDRADE; ROMEIRO, 2011).

Cavalcanti (2004) salienta que a economia ambiental insere o sistema ecológico na perspectiva da abordagem econômica. No entanto, a valoração econômica de recursos ambientais pode ser entendida como um conjunto de técnicas que sirvam ao propósito de ordenar opções excludentes, pois isso implica em estimar o valor monetário dos recursos ambientais em relação aos outros bens e serviços disponíveis na economia. Com base nessa mudança de foco econômico-financeiro a luta pela escassez requer um esforço social abrangente para conservar os estoques remanescentes de recursos naturais, além de tornar o seu uso mais inteligente. Assim, o grande desafio é aumentar consideravelmente a produtividade, com o menor uso possível dos recursos não renováveis (HU et al., 2011).

Coelho (2012) salienta que o efeito de transferência de custos da utilização dos recursos por um agente econômico a outro é denominado de "externalidade" ou "deseconomia externa". Não obstante, se faz necessário entender o papel de todos na sociedade dentro de um fluxo econômico com um funcionamento regular e livre, fluxo este em que as atividades de produção ou circulação de bens ou serviços não são impostas. A natureza é entendida neste sistema como um fator não contabilizado, ou seja, uma externalidade (LIMA, VIEGAS, 2002).

As externalidades são representadas pelo custo ou benefício que um agente, na realização de uma atividade econômica, impõe a terceiros, sendo que isto pode acontecer de forma positiva ou negativa sobre a atividade econômica, renda ou bem-estar de outro agente econômico, sem a correspondente compensação (COELHO, 2012). Vale destacar que as externalidades afetam a todos, pois são provenientes das ações que ecoam em toda a natureza interconectada de forma global (ELTZ, 2012).

Não obstante, quando uma externalidade é compensada ela deixa de ser uma externalidade, passando assim a ser internalizada. Assim, a questão a que se chega relaciona-se a transferência pela internalização do uso dos recursos naturais, sendo que estes não são renováveis e geram prejuízos à sociedade que não podem ser recuperados, a exemplo da saúde das pessoas. Além disso, um crescimento baseado na maximização dos lucros pela otimização na utilização dos recursos, com um viés monetário, que 
não contabiliza as externalidades negativas da produção, pode gerar problemas para todos a longo prazo (HENDERSON, 1996; BRAGATO et al., 2012).

Portanto, ao discutir produção e consumo deve-se analisar toda a cadeia de forma sistêmica e abrangente e não somente as transações comerciais. Essa perspectiva garante um uso mais consciente dos recursos, bem como compreender as responsabilidades e ações que deverão ser tomadas em cada etapa. Sendo que a utilização da metodologia de PML auxilia nesta tarefa ao estabelecer relações em cada fase da cadeia produtiva.

\section{Produção Mais Limpa - PML}

A sociedade contemporânea é obrigada a lidar com diversos problemas socioambientais que influenciam na qualidade de vida dos indivíduos, sendo que pode ser citado neste contexto de poluição do meio ambienta a emissão de gases de efeito estufa, além do descarte inadequado de resíduos. Vale destacar que a origem destes problemas está na ineficiência dos processos produtivos. Assim, a poluição do meio ambiente é oriunda, entre outras causas, dos resíduos (outputs) produzidos a partir da utilização de matériasprimas (inputs) que não foram aproveitadas adequadamente pelas empresas, sendo que este desperdício também compromete a produtividade e a competitividade das próprias empresas (CNTL, 2003; WEIHS; WEISSEL, 2005).

Portanto, ao tratar da cadeia de produção se faz necessário ressaltar que a implementação do modelo de PML exige que todo o processo produtivo seja analisado e avaliado (FÖRSTER, 2015). Aliás, devese verificar a eficiência do emprego de recursos e o consumo de energia em todas as etapas (MILAN; GRAZZIOTIN, 2012). Destaca-se que um aspecto relevante no modelo de PML é que se propõe a minimizar os problemas ambientais já na criação dos bens e serviços, ao invés de tratá-los depois que estes forem criados (VAN BERKEL et al., 2007).

A PML é constituída por um método que integra a estratégia econômica, tecnológica e ambiental aos processos de produção. Sua finalidade é a de aumentar a eficiência no uso de matérias-primas e insumos básicos por meio da redução dos desperdícios com a não geração, mitigação ou reciclagem de resíduos (ULUTAS, 2012). Além disso, a aplicação das práticas de PML permitem qualificar a empresa para o emprego eficiente de matérias-primas, pois exigem a aplicação de conhecimentos especializados específicos, de investimentos em tecnologia e mudanças de atitude das pessoas envolvidas no processo (BAAS, 1995; CNTL, 2003; STONE, 2006).

Portanto, a PML propõe a substituição do modelo industrial baseado no sistema end-of-pipe de inclusão de resíduos para posterior tratamento e descarte. Sendo que essa nova abordagem leva em conta os aspectos ambientais relacionados ao processo de produção, como o consumo de água e energia (DIÓGENES; FIGUEIREDO; PIMENTA, 2014). Além disso, há a utilização do conceito de melhoria contínua que permite aperfeiçoar a eficiência, a lucratividade e a competitividade das empresas (ALMEIDA; GIANNETTI, 2006; PIMENTA; GOVINHAS, 2012). Assim, ao melhorar seu desempenho com a utilização de PML constrói- 
se uma vantagem competitiva sustentável, para toda a cadeia de suprimentos e para as empresas (CNTL, 2003; MEDEIROS et al., 2007).

De acordo com a UNIDO (UNIDO, 2006), a PML consiste em uma estratégia preventiva e integrativa para a empresa, pois tais práticas são aplicadas em todo ciclo de produção o que proporciona: i) aumentar a produtividade por meio do uso mais eficiente de matéria-prima, energia e água; ii) promover melhorias no desempenho ambiental por meio da redução de fontes de desperdícios e emissão de gases e demais efluentes do processo; iii) reduzir o impacto ambiental oriundo do Ciclo de Vida de Produto - CVP.

Desse modo, as empresas devem identificar e analisar as fontes de poluição, bem como o seu monitoramento e controle, pois estes representam um primeiro passo no sentido de reduzir o impacto ambiental de seu processo produtivo (MILAN; GRAZZIOTIN , 2012; STRUGARIU; HEPUT 2012). Assim, cada atividade contribui para diminuir o uso de matérias-primas e energia, além de ajudar a prevenir ou mitigar a geração de resíduos (GIANNETTI et al., 2008).

A aplicação da metodologia de PML está dividida em três níveis. O Nível 1, representa a "Redução na Fonte", sendo promovido por medidas que visem evitar a geração de resíduos, efluentes e emissões. O Nível 2, representa a "Reciclagem Interna", assim os resíduos que não podem ser evitados, devem ser reintegrados ao processo de produção. Já o Nível 3, que representa a "Reciclagem Externa", esta opção ocorre quando não é possível buscar as soluções de eliminação ou redução na fonte e de reciclagem interna, então deve-se optar por medidas de reciclagem de resíduos e efluentes fora da empresa (CNTL, 2003, DIÓGENES; FIGUEIREDO; PIMENTA, 2014).

Um aspecto relevante na aplicação da metodologia de PML é que ela pode ser adotada em qualquer setor de atividade a partir de uma análise técnica, econômica e ambiental detalhada das operações, objetivando a identificação de oportunidades que possibilitem melhorar a eficiência sem acréscimo de custos para a empresa (DIÓGENES; FIGUEIREDO; PIMENTA, 2014). Assim, são priorizadas as ações que buscam a redução da geração dos resíduos na fonte geradora (nível 1), o que pode ser obtido por modificações no produto ou no processo produtivo (housekeeping, substituição de matérias-primas e modificações tecnológicas). Além disso, busca-se aperfeiçoar o ciclo produtivo interno da empresa (Nível 2), e quando não é possível mitigar os prejuízos ao meio ambiente pelos processos internos, são propostas medidas de reciclagem externa ou reaproveitamento em ciclos biogênicos (OLIVEIRA e ALVES, 2007).

Portanto, as práticas de PML podem envolver uma ou mais das seguintes mudanças: de processo industrial, de matérias-primas, de produto e de práticas de housekeeping. Muitas vezes uma simples mudança de layout ou uma melhor organização de um almoxarifado leva a economias que, se contabilizadas, mostram a eficácia da prevenção. A reciclagem interna, dentro do próprio processo produtivo, obtendo novos subprodutos ou aumentando a quantidade de produtos manufaturados, é mais uma alternativa a ser considerada na implantação de práticas de PML (ALMEIDA; GIANNETTI, 2006; VAN BERKEL et al., 2007; PIMENTA; GOVINHAS, 2012). 


\section{METODOLOGIA}

Este estudo que trata da aplicação do modelo de PML e as externalidades geradas na produção de serviços tem um caráter exploratório, pois visa ao longo do trabalho construir por meio do raciocínio indutivo reflexões que levem há proposições sobre o tema em pauta. Para tanto, destaca-se que a pesquisa exploratória proporciona maior familiaridade sobre o assunto proposto por meio do levantamento e análise de diversas fontes de evidências (CRESWELL, 2013). Tripodi, Fellin e Mayers (1981) salientam que o estudo exploratório fornece um quadro referencial que facilita o processo de construção de conceitos para levantar hipóteses na investigação de determinado fenômeno.

Quadro 1: Categorias de análise.

\begin{tabular}{|l|l|}
\hline CATEGORIA & AUTORES \\
\hline Externalidade & $\begin{array}{l}\text { CAVALCANTI, 2004; CAVALCANTI, 2010; BRAGATO et al., 2012; ELTZ, 2012; } \\
\text { COELHO, 2012 }\end{array}$ \\
\hline Produção de Serviços & Kotler (2006); LOVELOCK; WIRTZ (2006) \\
\hline \multirow{3}{*}{ PML } & $\begin{array}{l}\text { BAAS, 1995; CNTL, 2003; UNIDO, 2006; STONE, 2006 ALMEIDA; GIANNETTI, 2006; } \\
\text { LUKEN; NAVRATIL, 2007; VAN BERKEL et al., 2007; PIMENTA; GOVINHAS, 2012; } \\
\end{array}$ \\
\hline
\end{tabular}

No primeiro momento desse estudo foi empregada para obtenção dos dados a pesquisa bibliográfica e documental. Essa parte do trabalho foi primordial para a organização do componente conceitual e a construção das categorias de análise descritas no quadro 1. Essas categorias permitiram criar indicadores qualitativos, que permitiram a inferência dos conhecimentos obtidos das coletas de dados (CRESWELL, 2013).

A abordagem qualitativa utilizada neste estudo ajudou a compreender o evento da produção de serviços e os efeitos advindos desse processo. Assim, a reflexão proposta parte da análise da produção de serviços, no caso ilustrativo deste artigo, o pagamento de fatura em instituições bancárias. Assim, após a observação das etapas de início do processo e demanda pelo serviço, passou-se a analisar o fluxo da produção e entrega do serviço de recebimento de faturas. Desse modo, o uso de métodos qualitativos neste tipo de pesquisa facilitou o acesso às realidades sociais, além das interações entre as categorias de análise propostas e as evidências do processo de produção de serviços.

\section{RESULTADOS}

\section{Apresentação De Evidências Empíricas}

Inicialmente é importante delimitar o que se entende por serviços neste artigo, assim para a discussão sobre este setor ou atividade pode partir da definição genérica de que os serviços são os produtos que não são físicos (bens). De acordo com a classificação usada por Kotler (2006) e Lovelock e Wirtz (2006), tudo que é consumido pode ser categorizado como produtos, sendo que o ponto importante a ressaltar é que os produtos são divididos em dois grupos: i) bens: são produtos que se adquire a propriedade, os seus 
benefícios são percebidos pela durabilidade e tangibilidade; ii) serviços: são produtos que se adquire por meio de uma ação ou desempenho, ou seja, contrata-se um produto que é serviço pelo que o prestador faz (aula) ou promete fazer (seguro).

Além dessas diferenças entre os produtos que são bens dos que são serviços é importante destacar outras características como: os serviços são intangíveis e não podem ser estocados; os clientes podem ser envolvidos no processo de produção; outras pessoas também fazem parte do serviço, como os clientes; existe variabilidade na produção do serviço; e, os serviços são mais difíceis de serem avaliados do que os bens pela sua intangibilidade (LOVELOCK; WIRTZ, 2006; CORRÊA; CAON, 2006).

Portanto, após caracterizar o que é um produto que é serviço, se faz necessário desenhar um processo de entrega de serviços (figura 2), sendo que para facilitar a evidência da PML neste processo, este artigo se concentrará na utilização do papel como insumo principal na prestação de serviços bancários de recebimento de contas.

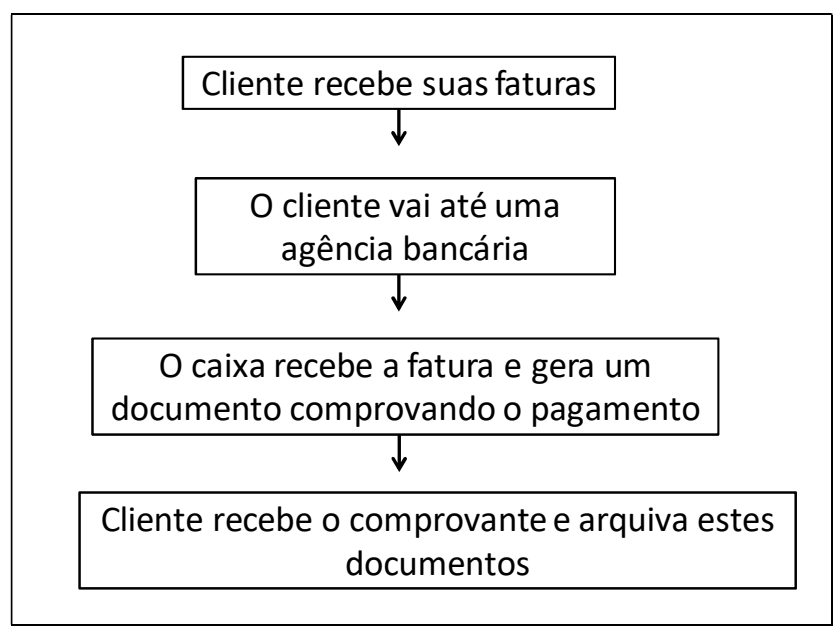

Figura 1: Processo de serviços de recebimento de fatura convencional.

Vale a pena ressaltar que a escolha pelo serviço bancário se dá pelo grau de importância e obrigatoriedade deste serviço, além de sua dimensão, pois somente os bancos do Brasil, Bradesco e Itaú possuíam respectivamente 35.933.973, 23.128.870 e 21.920.817 correntistas em 2010 (EXAME, 2011). Além disso, de acordo com a Febraban, em 2013 o número de correntistas no Brasil era de algo entorno de 103 milhões (VALOR, 2014).

Um fator relevante no processo de prestação de serviços pelos bancos é que neste tipo de serviço as operações eletrônicas atingiram já em 2013, segundo dados da Febraban, 16,6 bilhões de operações, um acréscimo de 18\% ante a produção destes serviços em 2012 (VALOR, 2014). Também em 2013, o número de contas com internet banking era de 41,8 milhões e as transações eletrônicas já representavam $41 \%$ do total dos bancos (FEBRABAN, 2015).

Segundo a Febraban (2015), o avanço na utilização dos serviços eletrônicos exige mais investimentos, mas a evolução da tecnologia e os ganhos de escala tornam este serviço mais eficiente e, consequentemente, de menor custo por operação do que o mesmo serviço de forma física. Não obstante, também podem ser adicionados como efeitos positivos desse novo processo, os benefícios que advêm da comodidade dessa 
nova forma de prestação de serviço. Desse modo, os correntistas podem realizar convenientemente seus pagamentos e demais operações financeiras em qualquer lugar. Sendo isso possível devido ao avanço da comunicação via internet, além da inserção de diversos equipamentos, como tablets e celulares, no processo de produção e entrega de serviços bancários.

A figura 3 demonstra esta nova realidade de prestação de serviços de recebimento de fatura pelos bancos. Diferentemente da realidade que obrigava a utilização de papel no processo de produção deste serviço, o que faz com que o cliente ao utilizar os meios eletrônicos não precise de nenhum tipo de papel para efetuar seus pagamentos.

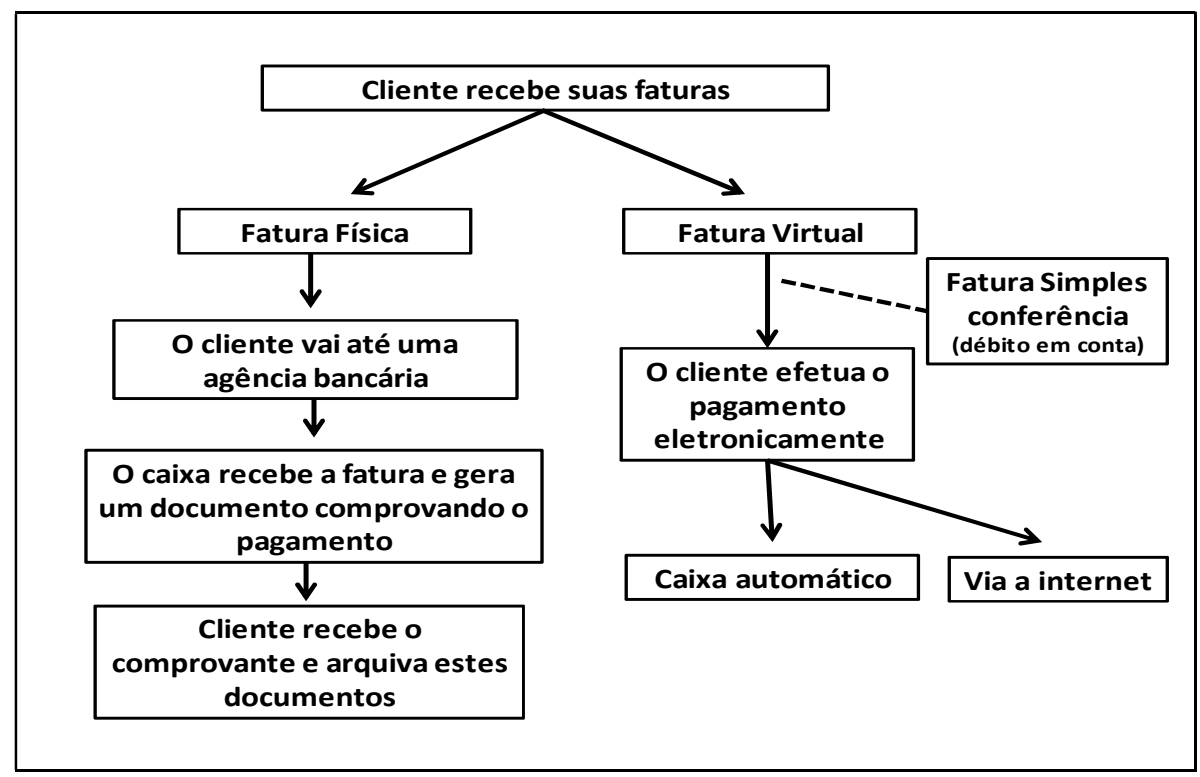

Figura 2: Processo de recebimento de fatura ampliado.

Como salientado anteriormente, este artigo visa evidenciar as externalidades do processo de produção de serviços, sendo utilizado o serviço de pagamento de faturas como mera ilustração. Deste modo, ao construir um modelo de análise para verificar a fluxo de produção desse serviço podem-se explorar os impactos gerados por todos os agentes nesse processo.

\section{DISCUSSÃO}

Cabe ressaltar que para analisar um processo de produção, seja ele de bens ou de serviços, se faz necessário integrar toda a cadeia. Desde o início, na ideia da criação do produto, na escolha de seus insumos, bem como na comercialização, consumo e descarte pelos clientes.

Embora na produção se um bem exista um controle maior da empresa produtora pelos insumos, processos e outros elementos relacionados a produção e consumo. Na atividade de produção e consumo de serviços, os clientes atuam como sujeitos ativos, inclusive sendo responsáveis pelos insumos para produção e entrega do serviço.

A figura 3 representa a relação entre os inputs e os outputs de um processo de pagamento de contas, além dos resultados oriundos desta dinâmica. Vale destacar que este fluxo linear sob a perspectiva da PML 
beneficia não somente os clientes e os bancos, mas toda sociedade com os efeitos ou a internalização dos prejuízos socioambientais advindos do seu processo.

Assim, ao apresentar um fluxo de produção de serviços pode ser notado que a aplicação da metodologia de PML auxilia em observar de forma sistêmica as etapas do processo de prestação deste serviço. Cabe aqui ressaltar que ao tratar deste fluxo verifica-se que por sua característica de produção, os serviços apresentam dificuldade para o acompanhamento das externalidades geradas em seu processo.

Com base no descrito na figura 3, o objetivo do cliente é ter uma fatura paga. No entanto, as diversas atividades desempenhadas nos serviços podem ser analisadas pela perspectiva da PML e aplicada sua metodologia para mitigar as externalidades. No caso em pauta, o uso do papel se torna desnecessário para esta prestação de serviços. Principalmente, após a incorporação de diversas tecnologias que facilitam as operações eletrônicas. Portanto, pode-se dizer que os três níveis de análise da PML subsidiam um desenho de processo mais consciente e controlado.

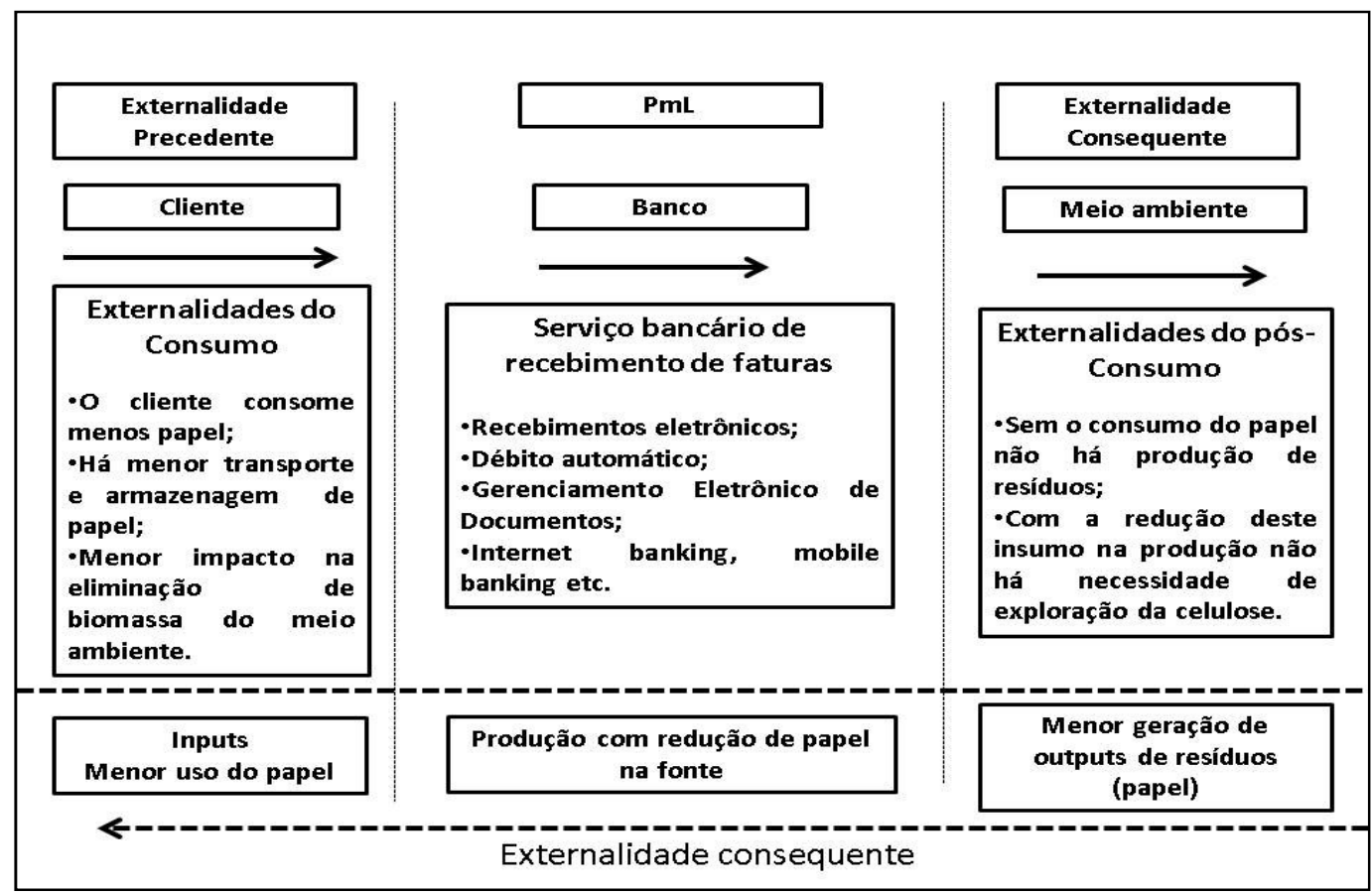

Figura 3: Fluxo de serviços bancários sob a perspectiva da PML.

No nível 1 (Redução na Fonte), mitiga-se as externalidades "Precedentes" relacionadas aos inputs do processo, pois o pagamento eletrônico, ou mesmo o débito automático de faturas, eliminam a necessidade de impressão de documentos. Esta etapa do processo reduz a demanda por papel, impressão, transporte, entre outros elementos ou atividades que podem gerar externalidades negativas ao ambiente e a sociedade.

No nível 2 (Reciclagem Interna), diversas atividades podem ser incorporadas como o GED (Gerenciamento Eletrônico de Documentos), além das plataformas virtuais de serviços. Assim, por não haver a necessidade de movimentar documentos físicos neste processo, ocorre uma considerável redução pela demanda por papéis. Vale destacar que somente em 2013, a FEBRABAN registrou 16,6 bilhões de operações eletrônicas (VALOR, 2014). 
No nível 3 (Reciclagem Externa), a externalidade progressiva verificada neste trabalho se dá de forma positiva. A redução no uso de papel no processo de produção de serviço diminui a geração de resíduos (outputs), o que contribui para mitigar a poluição em aterros sanitários, bem como o início de um novo ciclo de serviços que é a armazenagem e o tratamento destes resíduos.

Portanto, com base na descrição de um fluxo contínuo e circular, ao não utilizar o papel nestes pagamentos, obtém-se a externalidade positiva "consequente" na redução do uso de árvores e, consequentemente, a eliminação de biomassa do meio ambiente. Sendo que esta situação contribui para redução de dióxido de carbono da atmosfera.

\section{CONCLUSÕES}

Ao final desse estudo pode ser destacado que a aplicação do modelo de PML significa uma perspectiva responsável da organização para internalizar as externalidades negativas do processo de produção. O exemplo exposto para ilustrar a criação de um modelo que visualize as externalidades precedentes e consequentes do processo pode ser proposto em diversas atividades.

Não obstante, buscou-se explorar o fato de que a proposta da PML não se limita ao setor de manufatura. Contudo, a falta de perspectivas mais amplas de sua utilização pode conduzir a inferências reducionistas deste modelo. Nota-se que ao adotar a perspectiva de PML analise-se cada etapa, ou níveis, conduzindo uma observação do processo em busca de ações que mitigam a geração de externalidades negativas. Essas ações trazem benefícios não só de caráter ambiental ou social, mas também econômicofinanceiro para as empresas.

Outro ponto que merece destaque neste estudo é o tratamento que se dá à produção de serviços, pois suas especificidades exigem uma visão ampla e sistêmica do processo que deve incorporar partes intangíveis que não estão explicitas em cada etapa. Por outro lado, quando da produção de bens manufaturados, o projeto de produção contempla o processo de forma clara e controlável para cada insumo ou atividade. Já na produção de serviços, estes insumos ou atividades requerem um cuidado maior, pois como se trata de uma ação ou desempenho, que depende inclusive do próprio cliente para sua produção, o processo apresenta diversas partes que não estão sob o controle da empresa para a sua produção. Um exemplo pode ser o de um restaurante de autosserviço. A empresa produz o alimento, mas a entrega é feita pelo próprio cliente. Assim, como proposta de trabalho futuro é sugerido a realização de um experimento que contemple a produção de serviços e a utilização do modelo de PML.

\section{REFERÊNCIAS}

AKATU O dia “D” do consumo, 2008. Instituto Akatu.

ANDRADE, Daniel Caixeta; ROMEIRO, Ademar Ribeiro.

Degradação ambiental e teoria econômica: algumas reflexões sobre uma "Economia dos Ecossistemas".

Economia, v.12, n.1, p.3-26, jan/abr 2011. 
BAAS, L. Cleaner production: beyond projects. Journal of Cleaner Production, v. 3, 1995, pp. 55-59. Doi: http://dx.doi.org/10.1016/0959-6526(95)00042-D

BAUMAN, Zygmunt. Modernidade líquida. Rio de Janeiro: Jorge Zahar editor, 2001.

BAUMANN, H.; BOONS, F.; BRAGD, A.. Mapping the green product development field: engineering, policy and business perspectives. Journal of Cleaner Production, 10(5), 2002, p. 409-425. http://dx. doi.org/10.1016/S0959-6526(02)00015-X

BROWN, Lester R. Eco-Economia: construindo uma economia para a terra. Salvador: UMA, 2003.

CAVALCANTI, Clóvis. Uma tentativa de caracterização da economia ecológica. Ambiente \& Sociedade, v. 7, n. 1, 2004, p. $149-156$

CAVALCANTI, Clóvis. Concepções da economia ecológica: suas relações com a economia dominante e a economia ambiental. Estudos avançados, v. 24, n. 68, p. 53-67, 2010

COELHO, Fábio Ulhoa. Curso de direito comercial. v. 1, 16 ed. São Paulo: Saraiva, 2012.

CORRÊA, Henrique Luiz; CAON, Mauro. Gestão de serviços: lucratividade por meio de operações e de satisfação dos clientes. São Paulo: Atlas, 2006.

CNTL. Meio ambiente e a pequena e microempresa: módulo 1 - Curso de Formação de Consultores em Produção mais Limpa. Porto Alegre, 2003

CRESWELL, J. W. Research design: Qualitative, quantitative, and mixed Methods approaches. Sage, 2013.

DIÓGENES, Victor Hugo Dias; FIGUEIREDO, Lúcia Mara; PIMENTA, Handson Claudio Dias. Aplicação da Produção mais Limpa no setor de turismo: um estudo de caso em um hotel de Natal/RN. Revista GEPROS, n. 1, 2014, p. 141.

ELTZ, Magnum Koury de Figueiredo. Uma Abordagem da Análise Econômica do Direito para os Danos Ambientais Transfronteiriços. Economic Analysis of Law Review, v. 3, n. 1, 2012, p. 40-56. http://dx.doi.org/10.18836/21780587/ealr.v3n1p40-56

EXAME, Os dez bancos com mais correntistas no Brasil, 2011. http://exame.abril.com.br/revista-exame/noticias/os10-bancos-com-mais-correntistas-no-brasil\#3 Acesso março/2015.

FABI, M.; LOURENÇO, C.; SILVA, S. Consumo consciente: a atitude do cliente perante o comportamento sócioambiental empresarial. In: Encontro de Marketing da ANPAD (EMA), 4.Florianópolis, 23 a 25 de maio. 2010.

FEBRABAN. Pesquisa Febraban de Tecnologia Bancária 2013, 2015. Disponível em: <

http://www.febraban.org.br/7Rof7SWg6amyvwJcFwF7I0aS Df9jyV/sitefebraban/Pesquisa\%20FEBRABAN\%20de\%20Tecn ologia\%20Banc\%E1ria 2013.pdf> Acesso em: 08.03.2015.

GENG, Y., et al. Towards a national circular economy indicator system in China: an evaluation and critical analysis.
Journal of Cleaner Production, 23(1), 2012, p. 216-224.

http://dx.doi.org/10.1016/i.jclepro.2011.07.005

FÖRSTER, Bernadette. Technology foresight for sustainable production in the German automotive supplier industry. Technological Forecasting and Social Change, 92, 2015, 237248. http://dx.doi.org/10.1016/i.techfore.2014.09.010

GIANNETTI, B. F. et al. Cleaner production practices in a medium size gold-plated jewelry company in Brazil: when little changes make the difference. Journal of Cleaner Production, v. 16, n. 10, 2008, p. $1106-1117$. http://dx.doi.org/10.1016/j.jclepro.2007.06.002

G1, Economia brasileira avançou 2,3\% em 2013, diz IBGE, 2104.

http://g1.globo.com/economia/noticia/2014/02/economiabrasileira-avancou-23-em-2013-diz-ibge.html Acesso março/2015.

GHOSAL, Vivek. Business strategy and firm reorganization: role of changing environmental standards, sustainable business initiatives and global market conditions. Business Strategy and the Environment, 24.2, 2015, p. 123-144. http://dx.doi.org/10.1002/bse.1815

HARRISON, Rob. Pressure Groups, Campaigns and Consumers. In: ; NEWHOLM, Terry; SHAW, Deirdre (ed.). The Ethical Consumer. London: Sage, 2005, p. 55-67.

HENDERSON, Hazel. Building a win-win world: Life beyond global economic warfare. Berrett-Koehler Publishers, 1996.

$\mathrm{HU}$, J., et al. Ecological utilization of leather tannery waste with circular economy model. Journal of Cleaner Production, 19(2), 2011, p. 221-228. http://dx.doi.org/10.1016/j.jclepro.2010.09.018

JAPPUR, R. F. A sustentabilidade corporativa frente às diversas formações de cadeias produtivas segundo a percepção de especialistas. 2004. $161 \mathrm{f}$. Dissertação (Mestrado em Engenharia de Produção)-Universidade Federal de Santa Catarina, Florianópolis.

KOTLER, Philip; KELLER, Kevin L. Administração de Marketing. São Paulo: Pearson Prentice Hall, 2006.

LEITE, José Rubens Morato; SILVA, Leonio José Alves da. Juridicidade do Dano Ambiental: gestão da zona costeira e aspectos da exploração do pré-sal pelo Brasil. Sequência (Florianópolis), n. 65, 2012, p. 305-328.

LI, T.; CHEN, L. Analysis on the Circular Economy "Eleventh Five" Plans in Some Provinces. In: International Conference on Electronics, Information and Communication Engineering (EICE 2012). ASME Press, 2012.

LIMA, Diana Vaz de; VIEGAS, Waldyr. Tratamento contábil e evidenciação das externalidades ecológicas. Revista Contabilidade \& Finanças - USP, São Paulo, n. 30, p. 46 - 53, setembro/dezembro 2002.

LOVELOCK, Christopher; WIRTZ, Jochen. Marketing de Serviços. São Paulo: Pearson Prentice Hall, 2006.

LUKEN, R. A.; NAVRATIL, J. A programmatic review of UNIDO/UNEP national cleaner production centers. Journal 
of Cleaner Production, v. 12, 2007, p. 195-205.

http://dx.doi.org/10.1016/S0959-6526(03)00102-1

MILAN, G. S.; GRAZZIOTIN, D. B. Um estudo sobre a aplicação da Produção mais Limpa (P+L). GEPROS. Gestão da Produção, Operações e Sistemas, Ano 7, no 1, jan-mar/2012, 2012, p. 127-140.

PAREJA, Raúl Alexander Cardona. Fortalecimiento del desempeño ambiental empresarial, a través del programa de producción más limpia y consumo sostenible del Área Metropolitana del Valle de Aburrá. Producción+ Limpia, v. 5, n. 2, 2010, p. 9-23.

PIMENTA, Handson Claudio Dias; GOUVINHAS, Reidson Pereira. A produção mais limpa como ferramenta da sustentabilidade empresarial: um estudo no estado do Rio Grande do Norte. Revista Produção, v. 22, n. 3, 2012, p. 462476.

SEN, Amartya. Desenvolvimento como liberdade. São Paulo: Companhia das Letras, 2000.

STONE, L. Limitations of cleaner production programmes as organizational change agents. I. Achieving commitment and on-going improvement. Journal of Cleaner Production, $v$. 14, 2006, p. 1-14

http://dx.doi.org/10.1016/j.jclepro.2004.12.009

STRUGARIU, M. L.; HEPUT, T. Monitoring results on industrial wastewater pollutants in steel Industry. Acta Technical Corviniensis - Bulletin of engineering, v. 5, n. 4, 2012, p. 3336.

VAN BERKEL, R. Cleaner Production and Eco-efficiency initiatives in Western Australia. Journal of Cleaner
Production, v. 15, n. 8-9, p. 741-755, 2007.

http://dx.doi.org/10.1016/i.jclepro.2006.06.012

UNIDO. Cleaner Production Assessment in Dairy Processing, 2006. Disponível em: http://www.unep.fr/shared/publications/pdf/2480CpDairy.pdf Acesso março/2015.

TRIPODI, T., FELLIN, P.; MEYER, H. Análise da pesquisa social. Rio de Janeiro: Francisco Alves, 1981

ULUTAS, Ferda, et al. Determination of the framework conditions and research-development needs for the dissemination of cleaner (sustainable) production applications in Turkey. International Journal of Sustainable Development \& World Ecology, 19.3, 2012, p. 203-209. DOI: $\underline{10.1080 / 13504509.2011 .606550}$

VALOR, Número de contas correntes cresce $6 \%$ em 2013, à 103 milhões, 2014. Disponível em:

http://www.valor.com.br/financas/3531404/numero-decontas-correntes-no-brasil-cresce-6-em-2013-103-milhoes Acesso março/2015.

VARANDAS JR, A., MIGUEL, P., \& CARVALHO, M. Análise bibliométrica da literatura sobre os conceitos de Product Life Cycle Management, Product Development Process e Sustentabilidade e suas interfaces. In Anais... III International Workshop Advances in Cleaner Production, 2011.

WHITE HOUSE, Fact Sheet: President Obama to Announce Historic Carbon Pollution Standards for Power Plants, 2015. Disponível em: <https://www.whitehouse.gov/the-pressoffice/2015/08/03/fact-sheet-president-obama-announcehistoric-carbon-pollution-standards> Acesso em: 07.08.2015. 